\title{
Farklı Besi Sistemlerinde Besiye Alınan Saf ve Melez Oğlakların Vücut Kondisyon Puanı ve Vücut Ölçülerinin Karşılaştırılması
}

\author{
Hacer Tüfekci*, Mustafa Olfaz
}

Ondokuz Mayıs Üniversitesi, Ziraat Fakültesi, Zootekni Bölümü, 55139 Kurupelit/Samsun, Türkiye

\section{A K A L E B İ L G İ S İ}

Geliş 29 Ağustos 2016

Kabul 21 Kasim 2016

Çevrimiçi baskı, ISSN: 2148-127X

Anahtar Kelimeler:

Kıl keçi

Saanen x K1l keçi $\left(\mathrm{G}_{1}\right)$ melezi

Vücut kondisyon puanı

Vücut ölçüleri

Besi sistemi

*Sorumlu Yazar:

E-mail: tufekchacer@gmail.com

\section{Ö Z E T}

Bu çalışmada, entansif, yarı entansif ve ekstansif koşullarda besiye alınan Kıl keçi ve Saanen $\mathrm{x}$ Kıl keçi $\left(G_{1}\right)$ melezi erkek oğlakların vücut kondisyon puanı ve vücut ölçülerinin karşılaştırılması amaçlanmıștır. Araştırmada 30 baş Kıl keçisi ve 30 baş Saanen x Kıl keçi $\left(\mathrm{G}_{1}\right)$ melezi tekiz erkek oğlak kullanılmıştır. Araştırma bulguları değerlendirildiğinde, vücut kondisyon puanı bakımından 30, 60 ve 90. günlerde en yüksek değerler yarı entansif besi Saanen x Kıl keçi $\left(\mathrm{G}_{1}\right)$ melezi oğlaklarında tespit edilmiştir. Ancak besi sonunda yarı entansif besi grubu Kıl keçisi oğlakların en yüksek kondisyon puanı değerini gösterdiği belirlenmiștir. Bu durumun Kıl keçi oğlaklarında besinin ilerleyen aşamalarında çevre ve genişlik ölçülerinin Saanen x Kıl keçi $\left(\mathrm{G}_{1}\right)$ melezi oğlaklarına göre daha fazla artış göstermesinden kaynaklandığı düşünülmektedir. Çalışmada vücut uzunluğu açısından besinin bütün dönemlerinde, cidago yüksekliği bakımından ise 60 . ve 90 . günde elde edilen veriler istatistiki olarak önemli bulunmuştur. Besi sonunda yarı entansif besi grubundaki Saanen x Kıl keçi $\left(G_{1}\right)$ melezi oğlakların daha yüksek vücut uzunluğu ve daha az cidago yüksekliği değerlerine sahip oldukları gözlemlenmiştir. Kürekler arası göğüs geniş̧liği ölçüleri incelendiğinde bütün dönemlerde Kıl keçi oğlaklarında Saanen x Kıl keçi $\left(\mathrm{G}_{1}\right)$ melezi oğlaklarına göre daha fazla artı̧̧ olduğu görülmektedir. Sağrı yüksekliği bakımından besi sonunda Kıl keçisi oğlaklar Saanen x Kıl keçi $\left(G_{1}\right)$ melezi oğlaklardan daha yüksek değerler göstermiş olup en yüksek değeri yarı entansif grupta Kıl keçisi oğlaklar göstermiştir. Sonuç olarak yarı entansif besi grubu oğlakların vücut kondisyon puanı ve vücut ölçülerinin entansif ve ekstansif besi grubu oğlaklara göre daha yüksek olduğu, uzunluk ve yükseklik ölçüleri bakımından Saanen x Kıl keçi $\left(\mathrm{G}_{1}\right)$ melezi oğlakların, genişlik ve çevre ölçüleri bakımından Kıl keçi oğlakların daha yüksek değerler gösterdikleri söylenebilir.

Turkish Journal Of Agriculture - Food Science And Technology, 4(12): 1143-1148, 2016

Comparison of the Body Condition Score and Body Measurements of Purebred and Crossbred Kids Fattening in Different Systems

\section{A R T I C LE IN F O}

Article history:

Received 29 August 2016

Accepted 21 November 2016

Available online, ISSN: 2148-127X

Keywords:

Hair goat

Saanen x Hair goat $\left(\mathrm{G}_{1}\right)$

Body condition score

Body measurements

Fattening system.

*Corresponding Author:

E-mail: tufekchacer@gmail.com

\section{A B S T R A C T}

In this study was aimed to crossbred male kids of the Hair goat and Saanen x Hair kids $\left(\mathrm{G}_{1}\right)$ body condition score and compare their body size intensive, semi-intensive and extensive conditions. In the research, 30 Hair goat and 30 Saanen x Hair goat $\left(\mathrm{G}_{1}\right)$ crossbred single male kids was used. When the research findings were evaluated, in terms of body condition scores of 30,60 and $90^{\text {th }}$ days high values in the semi-intensive were detected in fattening Saanen $x$ Hair goat $\left(\mathrm{G}_{1}\right)$ crossbred kids. However, at the end of fattening in semi-intensive fattening group of Hair goat it is determined that the value of the highest condition score. This situation is thought to be caused by more growth of environment and width measurements in Hair goat kids in the later stages of fattening according to the Saanen x Hair goats $\left(\mathrm{G}_{1}\right)$ crossbred. In study in terms of body length during whole fattening, in terms of the height at the withers data obtained from the $60^{\text {th }}$ and $90^{\text {th }}$ day was found statistically significant. At the end of the fattening in semi-intensive fattening group of Saanen x Hair goat $\left(\mathrm{G}_{1}\right)$ crossbred it was observed to have higher body length and height at the withers value of crossbred kids. When chest width measurements between paddles in kids were examined, in all periods seems to be an increase in Hair goat kids than the Saanen x Hair goat $\left(\mathrm{G}_{1}\right)$ crossbred kids. At the end of fattening in terms of height rump Hair goats has shown higher values than Saanen x Hair goat $\left(\mathrm{G}_{1}\right)$ crossbred kids but the highest values of the semi-intensive group has shown. As a result, semi-intensive feeding group of kids of body condition score and body size was higher than intensive and extensive fattening group kids, in terms of length and height measurements Saanen $\mathrm{x}$ Hair goat $\left(\mathrm{G}_{1}\right)$ crossbred kids in terms of width and environmental measures has shown higher values than Hair goat kids. 


\section{Giriş}

Türkiye'de keçi yetiştiriciliği; doğal ve ekonomik koşullar, tarımsal yapı ve geleneklerden dolayı yaygın bir biçimde yapılmaktadır (Bolacalı, 2011). Türkiye İstatistik Kurumu verilerine göre Türkiye'de 10,416 milyon baş keçi bulunmakta olup sayısal olarak koyun ve sığırdan sonra üçüncü sırada gelmektedir (Anonim, 2016). Keçiler, yem kaynakları potansiyelinin ve özellikle sulama olanaklarının kısıtlı bulunduğu yörelerde mevcut yem kaynaklarını verimli bir biçimde değerlendirerek, yetiştiricilerin gereksinimi olan et ve süt gibi hayvansal ürünleri en ekonomik şekilde sağlayan hayvanlardır (Sandford, 1982; Yalçıntan ve ark., 2012). Keçi yetiştiriciliğinde elde edilen gelirler dikkate alındığında et üretimi diğer verimlere kıyasla önemli bir yere sahiptir. Vücut ölçüleri hayvanların morfolojik yapısı hakkında bilgi vermesi bakımından önemlidir. Et verimi vücut büyüklüğü ile yakından ilgilidir (Ünal, 2002; Sarı ve ark., 2014). Keçi yetiştiriciliğinde yüksek yapılı, bedeni uzun, geniş ve derin olan hayvanlar kullanılarak et üretiminde artış sağlanabilmektedir.

Hayvanlarda çeşitli karakterlerin, özellikle ekonomik olanların tespitinde canlı ağırlı önemli bir rol oynar. Doğum ağırlığı, erken gelişme, yemden yararlanma, büyüme hızı gibi parametreler ancak çeşitli dönemlerdeki canlı ağırlığın bilinmesi ile mümkündür. Hayvanlarda biyometrik ölçüler, çeşitli karakterlerinin değerlendirilmesinde kullanılmaktadır. Irk gelişimi, çevre ve beslenme faktörlerinin etkisiyle değişiklik gösteren özellikler için bu ölçüler önemli ipuçları sağlar (Riva ve ark., 2001). Beden ölçüleri, hayvanların morfolojik yapısı ve gelişme kabiliyeti hakkında bilgi vermesi bakımından da önemlidir. Çiftlik hayvanlarında beden ölçülerine bakılarak, canlı ağırlık tahmini çeşitli istatistiksel analiz yöntemleri kullanılarak yapılmaktadır (Gürcan, 2000). Hayvan yetiştiriciliğinde ele alınan verimlerin ve bunları etkileyen ölçütlerin kolay ve masrafsız belirlenmesi istenir. Verim özelliklerine ait veriler güç ve pahalı yöntemlerle elde ediliyorsa, bunun yerine dolaylı ölçütler üzerinde durulması başvurulabilecek bir yoldur. Ekonomik önemi olan özellikler kadar, beden ölçüleri ve diğer bazı kalitatif karakterler de bir ırk için tanıtıcı özelliklerdir. Bilhassa verim kontrollerinin yapılmadığ 1 durumlarda hayvanlar beden yapısina göre değerlendirilmektedir (Boztepe ve Dağ, 1995).

Vücut kondisyon puanlaması, hayvanın besi durumu ve yağlllık düzeylerinin yani enerji rezervlerinin değerlendirilmesi esasına dayanan subjektif bir uygulama olmasına rağmen, deneyimli kişiler tarafından kullanıldığında oldukça güvenilir bir yöntemdir (Wright ve Russel, 1984). Ayrıca vücut kondisyon puanlamasının hayvanlar için vücut kompozisyonuyla yakından ilişkisi olan basit işlevsel bir göstergeye dayalı, kullanışlı bir metottur (Rae, 2002).

Genel vücut durumu sürü içerisinde ne zaman azalmaya başlarsa, tamamlayıcı besleme ve mera gibi yönetim müdahalelerinin yapılması gerektiğinin bir işaretidir. Ancak keçiler her zaman gerçek durum anlatacak bir resim vermemektedir. Fiziksel olarak önemli noktalar üzerinde; omurganın her iki tarafinda ve omurga üzerinden durum değerlendirmesi yapılması gerekmektedir. Vücut kondisyon puanının 3 ile 2 vücut kondisyon puanı arasında olması ve yakından izlenerek bu puanlar arasında kalması sağlanmalıdır (Spahr, 2006).

Başarılı bir keçi yetiştiriciliğin en önemli şartı, yetiştiricilik yapılacak bölgenin coğrafik ve ekonomik şartlarına göre yetiştirme yönünün ve şeklinin iyi tespit edilmesi ve amaca uygun keçi ırkının isabetli seçilmesidir (Şimşek ve Bayraktar, 2007). Bu soruna çözüm bulmadaki temel yaklaşım, keçilerin genetik ve çevresel ıslahı olmalı ve buna yönelik farklı iyileştirme programları geliştirilmelidir. Ekonomik verimler ele alındığında hayvanın vücudundaki yağ doku rezervleri önem arz etmektedir. Çiftlik hayvanlarından elde edilen verimleri maksimum düzeyde tutmak için hayvanların optimum bir vücut kondisyonuna sahip olmaları gerekmektedir. İyileştirme çalışmaları vücut kondisyon puanı ile birlikte ele alınıp verim artırılmaya çalışılmalıdır. Böylece istenilen verim bakımından yapılacak çalışmalar vücut kondisyon puanı birlikte ele alındığında rantabilite yükselecektir (Biçer, 1991).

Bu çalışmanın amacı, Kıl keçi ve Saanen x Kıl keçi $\left(\mathrm{G}_{1}\right)$ melezi erkek oğlakların vücut kondisyon puanı ve vücut ölçülerinin belirlenmesi ve bu özellikler üzerine besleme şekli ve genotip faktörlerinin etkisini ortaya koymaktır.

\section{Materyal ve Yöntem}

Araştırmanın hayvan materyalini 2,5-3 aylık yaşta sütten kesilmiş 30 baş Kıl keçisi ve 30 baş Saanen x Kıl keçi $\left(\mathrm{G}_{1}\right)$ melezi tekiz erkek oğlaklar oluşturmuştur. Deneme Samsun ili Kavak ilçesi Yenigün Köyünde $\left(41^{\circ} 03^{\prime} 18^{\prime \prime} \mathrm{K}, \quad 36^{\circ} 06^{\prime} 56^{\prime \prime} \mathrm{D}\right)$ özel bir işletmede yürütülmüsstür. Oğlaklar işletmeye getirilerek iç ve dış parazit mücadeleleri ile şap, enterotoksemi aşıları yapılmıştır ve 2 haftalık bir alıştırma besisinden sonra denemeye başlanmıştır.

Entansif, yarı entansif ve ekstansif besiye alınan bütün hayvanların günlük kuru madde $(\mathrm{KM})$ esasına göre günlük besin madde gereksinimleri NRC (2001)'e göre canlı ağırlıklarının \%4,3'ü olarak belirlenmiştir. Entansif beside hayvanlar, kesif ve kaba yem oran 180/20 olan bir karma ile serbest (ad-libitum) yemlenmiştir. Yarı entansif beside hayvanların ihtiyaç duyduğu kuru madde miktarı biçme metodu ile haftalık olarak hesaplanarak mera tüketimi belirlenmiş ve geri kalan kısmı ise kesif yemden sağlanacak şekilde verilmiştir. Ekstansif gruptaki hayvanlara herhangi bir ilave yemleme yapılmamıştır. Sadece meradan faydalanmışlardır. Deneme boyunca oğlaklara temiz içme suyu ve yalama taşı ad-libitum olarak sağlanmıştır. Hayvanların entansif beslenmesinde kaba yem olarak kuru çayır otu, kesif yem olarak kuzu buzağı besi yemi kullanılmıştır. Beside kullanılan yemlerin ve meradan alınan örneklerin besin madde içerikleri Çizelge 1'de verilmiştir.

Araştırmada kullanılan 60 baş tekiz erkek oğlak; entansif, yarı entansif ve ekstansif olmak üzere üç farklı sistemde 150 gün besiye tabi tutulmuştur. Entansif ve yarı entansif besideki oğlakların hepsi bireysel bölmelerde $\left(1,5 \mathrm{~m}^{2}\right)$, ekstansif besideki oğlaklar ise grup olarak barındırılmıştır. Yarı entansif gruptaki oğlaklar gündüz meraya gitmiş ve akşam bireysel bölmelere 
yerleştirilmiştir. Deneme, tesadüf parsellerinde 2 (K1l keçi ve Saanen x Kıl keçi $\left(\mathrm{G}_{1}\right)$ melezi oğlak) x 3 (Entansif, yarı entansif ve ekstansif) faktöriyel deneme desenine göre yürütülmüştür.

Çalışmada vücut kondisyon puanı uygulaması 3 kişi tarafından aynı gün ve saatte, birbirlerinden bağımsız olarak yapılmıştır. Her hayvanın puanı, üç puantörün o hayvan için vermiş olduğu puanların ortalaması alınarak kabul edilmiştir. Vücut kondisyon puanlarının belirlenmesinde, Russel ve ark. (1969) tarafindan tanımlanan ve daha sonra Meat and Livestock Commission (1981) tarafından 0-5 aralığında geliştirilmiş olan puanlama metodu kullanılmıştır. Oğlakların besi başından besi sonuna kadar aylık olarak vücut ölçüleri alınmıştır. Cidago yüksekliği, sağrı yüksekliği, vücut uzunluğu, kürekler arası göğüs genişliği (K.A.G.G), göğüs derinliği ölçü bastonu ile gögüs çevresi, but çevresi ve ön incik çevresi ise ölçü şeridi ile tespit edilmiştir.

Denemede elde edilen veriler SPSS (Box ve ark., 1971) istatistik paket programında analiz edilmiştir. İncelen veriler üzerine besleme, genotip ve bunların interaksiyonlarının etkisini belirlemek için tesadüf parselleri deneme deseninde 2 × 3 faktöriyel analize tabi tutulmuştur. Analizde kullanılan model aşağıda verilmiştir.

$$
Y_{i j k}=\mu+G_{i}+B S_{j}+(G x B S)_{i j}+e i j k
$$

$\begin{array}{ll}\mu & : \text { populasyon ortalamasi } \\ G_{i} & : \text { i inci genotipin etkisi } \\ B S_{j} & : j \text { inci yetiştirme sisteminin etkisi } \\ (G x B S)_{i j} & : \text { i inci genotip ile } j \text { inci yetiştirme sisteminin } \\ & \quad \text { birlikte etkisi } \\ \text { eijk } & : \text { tesadüfi hata }\end{array}$

Çizelge 1 Beside kullanılan yemlerin ve meradan alınan örneklerin besin madde içerikleri (\%)

\begin{tabular}{l|ccc}
\hline \multicolumn{1}{c|}{ Besin maddeleri } & Kuru çayır otu & Konsantre Yem & Mera otu \\
\hline Kuru madde & 89,40 & 90,00 & 92,43 \\
Ham protein & 7,09 & 17,00 & 12,43 \\
Ham yağ & 1,25 & 3,00 & 2,91 \\
Ham selüloz & 34,90 & 10,00 & 28,74 \\
Ham kül & 8,01 & 9,00 & 8,84 \\
Organik madde & 81,36 & 81,00 & 83,37 \\
ADF & 41,58 & 21,61 & 31,32 \\
NDF & 67,89 & 42,17 & 51,27 \\
\hline
\end{tabular}

Çizelge 2 Besinin çeşitli dönemlerinde oğlakların vücut kondisyon puanı ( $\mathrm{n}=10, \overline{\mathrm{x}} \pm \mathrm{s} \overline{\mathrm{x}}$ )

\begin{tabular}{|c|c|c|c|c|c|c|c|}
\hline \multirow{2}{*}{$\begin{array}{l}\text { Tartım } \\
\text { günleri }\end{array}$} & \multicolumn{2}{|c|}{ Entansif Besi } & \multicolumn{2}{|c|}{ Yarı Entansif Besi } & \multicolumn{2}{|c|}{ Ekstansif Besi } & \multirow{2}{*}{$\mathrm{P}$} \\
\hline & KK & SK $\left(G_{1}\right)$ & $\mathrm{KK}$ & $\mathrm{SK}\left(\mathrm{G}_{1}\right)$ & KK & SK $\left(G_{1}\right)$ & \\
\hline Besi Başı & $2,94 \pm 0,10^{\mathrm{ab}}$ & $2,93 \pm 0,08^{\mathrm{ab}}$ & $3,10 \pm 0,10^{\mathrm{a}}$ & $3,08 \pm 0,14^{\mathrm{a}}$ & $3,00 \pm 0,13^{\mathrm{ab}}$ & $2,75 \pm 0,10^{b}$ & 0,020 \\
\hline 30. gün & $3,11 \pm 0,09^{\mathrm{ab}}$ & $3,00 \pm 0,07^{\mathrm{b}}$ & $3,18 \pm 0,05^{\mathrm{ab}}$ & $3,31 \pm 0,10^{\mathrm{a}}$ & $3,00 \pm 0,09^{b}$ & $2,95 \pm 0,06^{\mathrm{b}}$ & 0,028 \\
\hline 60. gün & $3,06 \pm 0,08^{\mathrm{ab}}$ & $2,98 \pm 0,08^{b}$ & $3,18 \pm 0,05^{\mathrm{ab}}$ & $3,25 \pm 0,10^{\mathrm{a}}$ & $2,98 \pm 0,10^{\mathrm{b}}$ & $2,95 \pm 0,06^{\mathrm{b}}$ & 0,047 \\
\hline 90. gün & $3,11 \pm 0,09^{\mathrm{ab}}$ & $3,00 \pm 0,07^{\mathrm{b}}$ & $3,18 \pm 0,05^{\mathrm{ab}}$ & $3,31 \pm 0,10^{\mathrm{a}}$ & $3,00 \pm 0,09^{b}$ & $2,95 \pm 0,06^{\mathrm{b}}$ & 0,028 \\
\hline 120. gün & $3,03 \pm 0,07$ & $3,31 \pm 0,32$ & $3,21 \pm 0,07$ & $3,28 \pm 0,15$ & $2,90 \pm 0,10$ & $2,98 \pm 0,08$ & 0,267 \\
\hline 150. gün & $2,96 \pm 0,04$ & $2,88 \pm 0,07$ & $3,25 \pm 0,00$ & $2,98 \pm 0,13$ & $3,00 \pm 0,10$ & $2,94 \pm 0,12$ & 0,462 \\
\hline
\end{tabular}

KK: Kıl keçi, SK $\left(\mathrm{G}_{1}\right)$ : Saanen x Kıl keçi $\left(\mathrm{G}_{1}\right)$, Aynı satırda farklı harflerle gösterilen ortalamalar arasındaki farklılık önemlidir $(\mathrm{P}<0,05)$

\section{Bulgular ve Tartışma}

\section{Vücut Kondisyon Puanı}

Elde edilen veriler incelendiğinde vücut kondisyon puanı bakımından 30, 60 ve 90. günlerde en yüksek değerler yarı entansif beside Saanen x K1l keçi $\left(\mathrm{G}_{1}\right)$ melezi oğlaklarda $(3,31,3,25,3,31)$ bulunmuştur. Kil keçi ve Saanen x Kıl keçi $\left(\mathrm{G}_{1}\right)$ melezi oğlakların besinin çeşitli dönemlerinde vücut kondisyon puanı değerleri Çizelge 2' de verilmiştir. Besinin bütün dönemlerinde genotipler arasında farklılıklar görülse de vücut kondisyon puanı üzerine genotip etkisi önemsiz bulunmuştur. Elde edilen veriler Konar Keskin (2010)'nin Kıl keçilerinde yaptığ çalışma sonucu $(3,00)$ ile benzerlik göstermektedir.

Besi sistemleri bakımından bir değerlendirme yapıldığında 30, 60 ve 90. gündeki elde edilen bulgularda yarı entansif besi grubundaki Kil keçi ve Saanen $x$ Kıl keçi $\left(\mathrm{G}_{1}\right)$ melezi oğlakların entansif ve ekstansif gruplardan daha yüksek değerler gösterdiği belirlenmiştir. Besinin 120 ve 150. günlerinde ise genotipler ve besi şekilleri arasında bir farklılığın olmadığı ve elde edilen vücut kondisyon puanı değerlerinin birbirine çok yakın olduğu görülmektedir. Ancak besi sonunda yarı entansif besi grubu Kıl keçisi oğlakların en yüksek kondisyon puanı değerini $(3,25)$ gösterdiği belirlenmiştir. $\mathrm{Bu}$ durumun Saanen x K1l keçi $\left(\mathrm{G}_{1}\right)$ melezi oğlakların K1l keçisi oğlaklarına göre vücut yapılarının daha ince ve vücutlarının daha uzun olmasından kaynaklandığı düşünülmektedir. Vücut kondisyon puanı bakımından besinin 30, 60 ve 90. günlerindeki farklılıkların 120 ve 150. günlerde görülmemesi, besi süresinin artması ile entansif besi grubundaki oğlakların bireysel bölmelerde strese girmelerine, yarı entansif ve ekstansif besi grubundaki oğlakların merada rahat ve özgür olmaları nedeniyle daha iyi sonuçlar alındığı göstermektedir.

\section{Vücut Ölçüleri}

Irk, cinsiyet, verim yönü ve yaş gibi faktörlere göre değişiklik gösteren vücut ölçüleri, hayvanların morfolojik yapısı ve gelişme kabiliyeti hakkında önemli bilgiler vermektedir. Oğlakların vücut ölçüleri besi başından itibaren 30 gün aralıklarla alınmıştır ve elde edilen veriler Çizelge 3' te verilmiştir. 
Çizelge 3 Besinin çeşitli dönemlerinde oğlakların vücut ölçüleri (cm, n=10, $\bar{x} \pm s \bar{x})$

\begin{tabular}{|c|c|c|c|c|c|c|c|}
\hline \multirow{2}{*}{$\begin{array}{l}\text { Vücut } \\
\text { ölçüleri }\end{array}$} & \multicolumn{2}{|c|}{ Entansif Besi } & \multicolumn{2}{|c|}{ Yarı Entansif Besi } & \multicolumn{2}{|c|}{ Ekstansif Besi } & \multirow{2}{*}{$\mathrm{P}$} \\
\hline & KK & $\mathrm{SK}\left(\mathrm{G}_{1}\right)$ & KK & $\operatorname{SK}\left(\mathrm{G}_{1}\right)$ & KK & SK $\left(\mathrm{G}_{1}\right)$ & \\
\hline $\begin{array}{l}\text { Besi Bş. } \\
\text { VU }\end{array}$ & $39,00 \pm 1,03^{\mathrm{b}}$ & $45,60 \pm 0,86^{\mathrm{a}}$ & $39,40 \pm 1,02^{\mathrm{b}}$ & $44,80 \pm 1,28^{\mathrm{a}}$ & $38,90 \pm 0,96^{\mathrm{b}}$ & $45,50 \pm 0,72^{\mathrm{a}}$ & $<0,001$ \\
\hline CY & $45,78 \pm 0,64$ & $47,90 \pm 1,11$ & $45,90 \pm 0,86$ & $47,60 \pm 0,76$ & $46,40 \pm 0,93$ & $48,10 \pm 0,57$ & 0,197 \\
\hline K.A.G.G & $11,22 \pm 0,43^{\mathrm{b}}$ & $13,40 \pm 0,56^{\mathrm{a}}$ & $11,40 \pm 0,45^{\mathrm{b}}$ & $11,80 \pm 0,42^{b}$ & $11,00 \pm 0,39^{b}$ & $11,60 \pm 0,27^{\mathrm{b}}$ & 0,003 \\
\hline GD & $17,22 \pm 0,43^{\mathrm{cd}}$ & $18,50 \pm 0,43^{\mathrm{abc}}$ & $17,70 \pm 0,37^{\mathrm{bcd}}$ & $18,80 \pm 0,53^{\mathrm{ab}}$ & $16,60 \pm 0,73^{\mathrm{d}}$ & $19,20 \pm 0,20^{\mathrm{a}}$ & 0,002 \\
\hline SY & $46,67 \pm 0,80^{\mathrm{b}}$ & $48,90 \pm 0,95^{\mathrm{ab}}$ & $47,00 \pm 0,89^{\mathrm{b}}$ & $48,70 \pm 0,80^{\mathrm{ab}}$ & $47,30 \pm 0,86^{\mathrm{ab}}$ & $49,60 \pm 0,52^{\mathrm{a}}$ & 0,043 \\
\hline GÇ & $50,44 \pm 0,73$ & $53,80 \pm 1,26$ & $51,80 \pm 1,66$ & $54,30 \pm 1,33$ & $52,40 \pm 0,76$ & $54,80 \pm 0,79$ & 0,091 \\
\hline ÖİÇ & $6,67 \pm 0,17^{\mathrm{c}}$ & $7,45 \pm 0,14^{\mathrm{ab}}$ & $7,00 \pm 0,21 b^{c}$ & $7,30 \pm 0,13^{\mathrm{ab}}$ & $7,10 \pm 0,18^{\mathrm{abc}}$ & $7,60 \pm 0,15^{\mathrm{a}}$ & 0,004 \\
\hline $\mathrm{BÇ}$ & $45,11 \pm 1,44$ & $47,00 \pm 0,87$ & $45,40 \pm 1,11$ & $47,10 \pm 0,72$ & $46,00 \pm 1,06$ & $46,70 \pm 0,58$ & 0,611 \\
\hline \multicolumn{8}{|l|}{ 30. gün } \\
\hline VU & $46,89 \pm 0,89^{\mathrm{ab}}$ & $48,60 \pm 0,54^{\mathrm{a}}$ & $45,00 \pm 1,09^{\mathrm{bc}}$ & $48,00 \pm 0,75^{\mathrm{a}}$ & $43,10 \pm 0,90^{\mathrm{c}}$ & $47,40 \pm 0,50^{\mathrm{ab}}$ & $<0,001$ \\
\hline CY & $50,11 \pm 0,79$ & $49,50 \pm 0,98$ & $51,30 \pm 1,15$ & $49,78 \pm 0,97$ & $48,70 \pm 0,80$ & $49,40 \pm 0,75$ & 0,470 \\
\hline K.A.G.G & $11,78 \pm 0,40^{\mathrm{bc}}$ & $13,10 \pm 0,66^{\mathrm{ab}}$ & $10,90 \pm 0,72^{c}$ & $13,67 \pm 0,80^{\mathrm{a}}$ & $11,80 \pm 0,20^{\mathrm{bc}}$ & $13,70 \pm 0,65^{\mathrm{a}}$ & 0,006 \\
\hline GD & $19,11 \pm 0,39^{b}$ & $20,50 \pm 0,34^{\mathrm{a}}$ & $19,30 \pm 0,37^{\mathrm{b}}$ & $20,67 \pm 0,33^{\mathrm{a}}$ & $19,10 \pm 0,35^{\mathrm{b}}$ & $20,70 \pm 0,21^{\mathrm{a}}$ & $<0,001$ \\
\hline SY & $51,22 \pm 0,64$ & $51,50 \pm 1,17$ & $51,40 \pm 0,72$ & $51,44 \pm 0,80$ & $49,10 \pm 0,92$ & $52,10 \pm 0,55$ & 0,176 \\
\hline GÇ & $62,67 \pm 1,37^{\mathrm{b}}$ & $63,40 \pm 1,78^{\mathrm{ab}}$ & $63,10 \pm 0,78^{\mathrm{ab}}$ & $67,44 \pm 2,04^{\mathrm{a}}$ & $56,60 \pm 1,57^{\mathrm{c}}$ & $58,50 \pm 0,93^{\mathrm{c}}$ & $<0,001$ \\
\hline ÖİÇ & $7,61 \pm 0,16$ & $7,40 \pm 0,15$ & $7,16 \pm 0,19$ & $7,61 \pm 0,18$ & $7,30 \pm 0,11$ & $7,20 \pm 0,13$ & 0,176 \\
\hline $\mathrm{BÇ}$ & $67,67 \pm 0,73$ & $69,90 \pm 1,93$ & $68,90 \pm 1,52$ & $71,44 \pm 2,03$ & $69,40 \pm 1,24$ & $70,20 \pm 0,99$ & 0,628 \\
\hline \multicolumn{8}{|l|}{ 60. gün } \\
\hline VU & $48,78 \pm 0,86^{\mathrm{a}}$ & $50,00 \pm 0,87^{\mathrm{a}}$ & $48,60 \pm 1,00^{\mathrm{a}}$ & $51,44 \pm 1,00^{\mathrm{a}}$ & $45,30 \pm 0,99^{b}$ & $48,90 \pm 0,85^{\mathrm{a}}$ & 0,001 \\
\hline CY & $52,78 \pm 0,68^{\mathrm{a}}$ & $49,90 \pm 0,59^{b}$ & $53,20 \pm 0,87^{\mathrm{a}}$ & $50,78 \pm 1,23^{\mathrm{ab}}$ & $48,90 \pm 0,75^{\mathrm{b}}$ & $50,80 \pm 0,55^{\mathrm{ab}}$ & 0,002 \\
\hline K.A.G.G & $12,11 \pm 0,31^{\mathrm{abc}}$ & $11,70 \pm 0,33^{\mathrm{bc}}$ & $12,80 \pm 0,49^{\mathrm{ab}}$ & $13,11 \pm 0,35^{\mathrm{a}}$ & $11,30 \pm 0,45^{\mathrm{c}}$ & $11,90 \pm 0,31^{\mathrm{bc}}$ & 0,015 \\
\hline GD & $21,56 \pm 0,29^{\mathrm{a}}$ & $20,70 \pm 0,45^{\mathrm{ab}}$ & $20,80 \pm 0,25^{\mathrm{ab}}$ & $21,78 \pm 0,28^{\mathrm{a}}$ & $20,20 \pm 0,44^{\mathrm{b}}$ & $21,20 \pm 0,29^{\mathrm{ab}}$ & 0,026 \\
\hline SY & $53,56 \pm 0,58^{\mathrm{ab}}$ & $50,90 \pm 0,38^{c}$ & $54,40 \pm 0,97^{\mathrm{a}}$ & $54,00 \pm 1,14^{\mathrm{a}}$ & $51,30 \pm 0,93^{b c}$ & $52,70 \pm 0,58^{\mathrm{abc}}$ & 0,012 \\
\hline GÇ & $66,78 \pm 1,69^{\mathrm{ab}}$ & $67,80 \pm 1,41^{\mathrm{a}}$ & $67,00 \pm 0,77^{\mathrm{ab}}$ & $69,44 \pm 1,53^{\mathrm{a}}$ & $63,60 \pm 0,86^{\mathrm{b}}$ & $66,30 \pm 0,99^{\mathrm{ab}}$ & 0,047 \\
\hline ÖİÇ & $7,33 \pm 0,29$ & $7,55 \pm 0,16$ & $7,70 \pm 0,15$ & $7,83 \pm 0,17$ & $7,60 \pm 0,16$ & $7,90 \pm 0,18$ & 0,338 \\
\hline $\mathrm{BÇ}$ & $71,56 \pm 1,18$ & $71,00 \pm 1,19$ & $73,70 \pm 1,04$ & $72,33 \pm 1,28$ & $70,70 \pm 0,86$ & $71,20 \pm 0,90$ & 0,378 \\
\hline \multicolumn{8}{|l|}{ 90. gün } \\
\hline VU & $53,11 \pm 0,92^{\mathrm{abc}}$ & $55,22 \pm 0,91^{\mathrm{a}}$ & $52,20 \pm 0,88^{\mathrm{bc}}$ & $55,44 \pm 1,06^{\mathrm{a}}$ & $50,30 \pm 1,01^{\mathrm{c}}$ & $53,90 \pm 0,90^{\mathrm{ab}}$ & 0,003 \\
\hline CY & $56,00 \pm 0,53^{\mathrm{ab}}$ & $54,00 \pm 0,87^{\mathrm{bc}}$ & $57,10 \pm 0,71^{\mathrm{a}}$ & $54,56 \pm 0,94^{\mathrm{abc}}$ & $54,20 \pm 1,31^{\mathrm{bc}}$ & $52,90 \pm 0,72^{\mathrm{c}}$ & 0,020 \\
\hline K.A.G.G & $12,89 \pm 0,35^{\mathrm{bc}}$ & $14,44 \pm 0,38^{\mathrm{a}}$ & $12,60 \pm 0,45^{\mathrm{bc}}$ & $13,33 \pm 0,37^{\mathrm{ab}}$ & $11,80 \pm 0,36^{\mathrm{c}}$ & $13,40 \pm 0,40^{\mathrm{ab}}$ & 0,001 \\
\hline GD & $22,22 \pm 0,40^{\mathrm{bc}}$ & $22,33 \pm 0,24^{b c}$ & $22,80 \pm 0,33^{\mathrm{b}}$ & $24,00 \pm 0,37^{\mathrm{a}}$ & $21,60 \pm 0,34^{\mathrm{c}}$ & $23,10 \pm 0,38^{\mathrm{ab}}$ & $<0,001$ \\
\hline SY & $56,56 \pm 0,65$ & $56,22 \pm 0,83$ & $58,30 \pm 0,73$ & $57,44 \pm 1,06$ & $55,20 \pm 1,15$ & $55,70 \pm 0,68$ & 0,135 \\
\hline GÇ & $70,67 \pm 1,19$ & $70,78 \pm 1,44$ & $71,30 \pm 1,34$ & $73,78 \pm 0,89$ & $69,60 \pm 0,73$ & $71,70 \pm 1,19$ & 0,224 \\
\hline ÖİÇ & $8,33 \pm 0,17$ & $8,22 \pm 0,15$ & $8,20 \pm 0,20$ & $8,44 \pm 0,18$ & $8,20 \pm 0,20$ & $8,00 \pm 0,15$ & 0,611 \\
\hline $\mathrm{BC}$ & $75,22 \pm 1,08^{\mathrm{b}}$ & $75,33 \pm 1,90^{\mathrm{b}}$ & $80,00 \pm 0,60^{\mathrm{a}}$ & $77,89 \pm 1,30^{\mathrm{ab}}$ & $74,60 \pm 0,95^{\mathrm{b}}$ & $76,00 \pm 1,20^{\mathrm{b}}$ & 0,020 \\
\hline \multicolumn{8}{|l|}{ 120. gün } \\
\hline VU & $53,00 \pm 0,83^{b c}$ & $54,75 \pm 1,01^{\mathrm{ab}}$ & $51,25 \pm 0,53^{\mathrm{cd}}$ & $55,00 \pm 0,50^{\mathrm{ab}}$ & $50,40 \pm 1,02^{\mathrm{d}}$ & $55,40 \pm 0,40^{\mathrm{a}}$ & $<0,001$ \\
\hline CY & $57,89 \pm 0,72$ & $54,63 \pm 1,02$ & $57,63 \pm 1,21$ & $56,38 \pm 0,65$ & $55,90 \pm 1,22$ & $56,20 \pm 0,63$ & 0,199 \\
\hline K.A.G.G & $14,22 \pm 0,36$ & $14,38 \pm 0,38$ & $14,38 \pm 0,38$ & $14,63 \pm 0,26$ & $13,80 \pm 0,29$ & $14,30 \pm 0,40$ & 0,679 \\
\hline GD & $22,78 \pm 0,36^{\mathrm{b}}$ & $23,63 \pm 0,42^{\mathrm{ab}}$ & $23,63 \pm 0,32^{\mathrm{ab}}$ & $24,75 \pm 0,25^{\mathrm{a}}$ & $22,70 \pm 0,52^{\mathrm{b}}$ & $24,50 \pm 0,40^{\mathrm{a}}$ & 0,002 \\
\hline SY & $60,22 \pm 0,72$ & $58,13 \pm 0,91$ & $60,13 \pm 1,11$ & $59,13 \pm 0,40$ & $58,20 \pm 0,94$ & $59,10 \pm 0,90$ & 0,396 \\
\hline GÇ & $73,89 \pm 1,56^{\mathrm{b}}$ & $73,63 \pm 1,34^{\mathrm{b}}$ & $73,00 \pm 1,84^{b}$ & $78,13 \pm 1,37^{\mathrm{a}}$ & $73,50 \pm 1,21^{\mathrm{b}}$ & $73,60 \pm 0,81^{\mathrm{b}}$ & 0,041 \\
\hline ÖİÇ & $8,11 \pm 0,20$ & $8,13 \pm 0,23$ & $7,94 \pm 0,15$ & $8,38 \pm 0,18$ & $8,00 \pm 0,00$ & $8,10 \pm 0,10$ & 0,497 \\
\hline $\mathrm{BÇ}$ & $79,33 \pm 0,58^{\mathrm{b}}$ & $77,88 \pm 1,87^{\mathrm{b}}$ & $84,38 \pm 1,21^{\mathrm{a}}$ & $81,13 \pm 2,03^{a b}$ & $78,30 \pm 1,47^{\mathrm{b}}$ & $78,60 \pm 1,76^{\mathrm{b}}$ & 0,043 \\
\hline \multicolumn{8}{|l|}{ 150. gün } \\
\hline VU & $54,29 \pm 1,06^{\mathrm{bc}}$ & $56,25 \pm 0,63^{b}$ & $52,00 \pm 0,10^{\mathrm{a}}$ & $57,50 \pm 0,50^{b}$ & $52,00 \pm 1,29^{\mathrm{c}}$ & $56,25 \pm 1,03^{b}$ & 0,012 \\
\hline CY & $60,00 \pm 0,76$ & $55,25 \pm 1,25$ & $60,00 \pm 0,30$ & $58,00 \pm 3,00$ & $59,00 \pm 1,63$ & $56,25 \pm 0,85$ & 0,064 \\
\hline K.A.G.G & $14,57 \pm 0,43$ & $14,50 \pm 0,50$ & $14,50 \pm 0,25$ & $14,00 \pm 0,50$ & $14,00 \pm 0,25$ & $13,25 \pm 0,71$ & 0,376 \\
\hline GD & $23,86 \pm 0,40$ & $23,75 \pm 0,48$ & $25,00 \pm 0,15$ & $25,00 \pm 0,30$ & $24,50 \pm 0,29$ & $24,50 \pm 0,87$ & 0,541 \\
\hline SY & $61,71 \pm 0,89^{\mathrm{a}}$ & $57,75 \pm 1,25^{\mathrm{b}}$ & $62,00 \pm 0,20^{\mathrm{a}}$ & $59,00 \pm 1,00^{\mathrm{ab}}$ & $59,50 \pm 0,50^{\mathrm{ab}}$ & $57,25 \pm 0,85^{\mathrm{b}}$ & 0,013 \\
\hline GÇ & $76,29 \pm 1,29^{\mathrm{a}}$ & $70,75 \pm 2,43^{\mathrm{b}}$ & $75,00 \pm 0,50^{\mathrm{ab}}$ & $78,00 \pm 0,40^{\mathrm{a}}$ & $77,50 \pm 0,65^{\mathrm{a}}$ & $74,00 \pm 0,71^{\mathrm{ab}}$ & 0,044 \\
\hline ÖİÇ & $8,57 \pm 0,20$ & $8,25 \pm 0,25$ & $8,00 \pm 0,60$ & $8,00 \pm 0,35$ & $8,25 \pm 0,25$ & $8,50 \pm 0,29$ & 0,559 \\
\hline $\mathrm{BÇ}$ & $82,71 \pm 2,33$ & $76,00 \pm 2,08$ & $88,00 \pm 0,70$ & $78,50 \pm 5,50$ & $85,00 \pm 1,08$ & $80,75 \pm 2,81$ & 0,108 \\
\hline
\end{tabular}

KK: Kıl keçi, SK $\left(\mathrm{G}_{1}\right)$ : Saanen x Kıl keçi $\left(\mathrm{G}_{1}\right)$, VU: Vücut Uzunluğu, CY: Cidago Yüksekliği, GD: Göğüs Derinliği, SY: Sağrı Yüksekliği, GÇ: Göğüs Çevresi, ÖIÇ: Ön İncik Çevresi, BÇ: But Çevresi, Aynı satırda farklı harflerle gösterilen ortalamalar arasındaki farklılık çok önemlidir ( $\mathrm{P}<0,001)$, KAGG: Kürekler arası göğüs genişliği 
Elde edilen veriler incelendiğinde; vücut uzunluğu açısından besinin bütün dönemlerinde gruplar arası farklılıklar istatistik olarak önemli bulunmuştur $(\mathrm{P}<0,05)$. Besi başında en yüksek değeri entansif besi grubundaki Saanen x K1l keçi $\left(\mathrm{G}_{1}\right)$ melezi oğlaklar gösterirken; besi sonunda yarı entansif besi grubundaki Saanen x Kıl keçi $\left(G_{1}\right)$ melezi oğlakların daha yüksek değere sahip olduğu gözlemlenmiştir. $\mathrm{Bu}$ sonuç besinin ilerlemesine paralel olarak oğlakların merada hareket etmesinin de etkisiyle yarı entansif grupta daha iyi bir vücut gelişimi sağlandığını göstermektedir. Besi sonunda elde edilen değerler Şimşek ve Bayraktar (2006)'ın Kıl keçi ve Saanen x Kıl keçi melezi $\left(\mathrm{F}_{1}\right)$ oğlaklarda yaptığı çalışma sonuçları ile $(55,55 \mathrm{~cm}, 56,62 \mathrm{~cm})$ benzer, Tozlu (2006) tarafından aynı ırklarla yapılan çalışmada elde edilen vücut uzunluğu değerlerinden ise yüksek bulunmuştur.

Cidago yüksekliği bakımından 60. ve 90. günde elde edilen veriler istatistiki olarak önemli bulunmuştur $(\mathrm{P}<0,05)$. Besi sonuna bakıldığında yarı entansif besi grubundaki oğlakların daha fazla cidago yüksekliğine sahip olduğu görülmektedir fakat istatistiki olarak önemli bir farklılık bulunmamıştır. Elde edilen 90. gün verileri Şimşek ve ark. (2007) tarafından Saanen x Kıl keçi $\left(F_{1}\right)$ ve $\left(\mathrm{G}_{1}\right)$ melezi oğlaklarda yaptıkları çalışma sonucunda elde edilen değerlerden yüksek bulunmuştur.

Oğlaklarda kürekler arası göğüs genişliği ölçüleri incelendiğinde besi baş1, 30. gün, 60. gün ve 90. gündeki elde edilen bulgular istatistik olarak önemli bulunmuştur $(\mathrm{P}<0,05)$. Besinin bütün dönemlerine bakıldığında Kıl keçi oğlaklarında Saanen $\mathrm{x}$ Kıl keçi $\left(\mathrm{G}_{1}\right)$ melezi oğlaklarına göre kürekler arası göğüs genişliği ölçülerinde daha fazla artış olduğu görülmektedir. Bu durum Kıl keçi oğlaklarının vücut uzaması değil de vücut kalınlaşması şeklinde bir gelişim gösterdiğini ortaya koymuştur.

Göğüs derinliği ve gögüs çevresi verileri incelendiğinde besi genelinde Kıl keçi oğlaklarında Saanen x K1l keçi $\left(G_{1}\right)$ melezi oğlaklarına göre daha yüksek değerler olmasına karşın besi sonunda göğüs derinliği verileri gruplar içerisinde birbirine çok yakın değerler göstermiştir. Saanen x K1l keçi $\left(\mathrm{G}_{1}\right)$ melezi oğlaklarından elde edilen 90. gün değerleri Bolacalı ve Küçük (2012)'ün Saanen oğlaklarında yaptıkları çalışma sonuçlarından $(21,60,53,50)$ yüksek bulunmuştur

Sağrı yüksekliği bakımından besi başında Saanen $\mathrm{x}$ Kıl keçi $\left(G_{1}\right)$ melezi oğlakları Kıl keçi oğlaklarına göre daha yüksek değerler göstermesine karşın besi sonunda Kil keçisi oğlaklar Saanen $x$ Kil keçi $\left(G_{1}\right)$ melezi oğlaklardan daha yüksek değerler göstermiş olup en yüksek değeri yarı entansif grupta Kıl keçisi oğlaklar $(62,00 \pm 0,20)$ göstermiştir.

Oğlakların büyümesinin doğal bir sonucu olarak, besi dönemlerinin ilerlemesine paralel bir şekilde oğlakların vücut ölçülerinde düzenli bir artış görülmüştür. Genotipler arasında bir değerlendirme yapıldığında uzunluk ve yükseklik ölçüleri bakımından Saanen x K1l keçi $\left(G_{1}\right)$ melezi oğlakların, Kıl keçi oğlaklarından genel olarak daha yüksek değerler göstermiştir. Ancak genişlik ve çevre ölçüleri bakımından Kıl keçi oğlakları daha yüksek değerler göstermiştir. Besi yöntemleri bakımından bir değerlendirme yapıldığında, yükseklik ölçüleri bakımından ekstansif gruptan entansif gruba doğru, hem K1l keçi hem Saanen x K1l keçi $\left(\mathrm{G}_{1}\right)$ melezi oğlaklarda bir artışın olduğu söylenebilir. Ancak vücut çevresi ölçüleri bakımından yarı entansif grubun diğer gruplardan daha yüksek değerler gösterdiği tespit edilmiştir.

\section{Sonuç ve Öneriler}

Ülkemizde genel olarak meraların yetersiz olması nedeniyle küçükbaş hayvanlarda kondisyon yetersizliği söz konusudur. Bu durumdaki hayvanlarda vücut ölçüleri ve vücut kondisyon puanlaması yapılarak duruma göre ek yemleme yapilması zorunlu hale gelebilir. $\mathrm{Bu}$ nedenle sürüde vücut kondisyon puanının takip edilerek zamanında önlem alınması sağlanabilir.

$\mathrm{Bu}$ çalışmada elde edilen vücut kondisyon puanı ve vücut ölçüleri değerlendirildiğinde, yarı entansif besi grubu oğlakların daha yüksek değerler gösterdiği belirlenmiştir. Keçiler mizaç olarak doğayı, gezmeyi ve otlamayı seven hayvanlardır. Keçilerin besisinde günün belirli bir zamanında mutlaka hayvanların meraya salınması içeri girdiklerinde ihtiyaç kadar kesif yem verilmesi gerekmektedir.

Sonuç olarak yetiştiricilere, yarı entansif besi yönteminin her iki genotip içinde daha tercih edilebilir bir besi yöntemi olduğu, aynı zamanda hayvan refahı açısından da bu yöntemin tercih edilmesi gerektiği önerilebilir.

\section{Kaynaklar}

Anonim 2016. http://www.tuik.gov.tr, Erişim Tarihi: 09.10.2016.

Biçer O. 1991. Koyunlarda Vücut Kondisyon Puanlaması ve Koyun Yetiştiriciliğinde Önemi. Çukurova Üniversitesi, Ziraat Fakültesi Dergisi, 6:4,81-89.

Bolacalı M, Küçük M. 2011. Muş Bölgesinde Yetiştirilen Saanen Oğlaklarının Büyüme Performans1 ve Yaşama Gücü. Iğdır Üniversitesi, Fen Bilimleri Enstitüsü Dergisi 1:2, 125131.

Bolacalı M, Küçük M. 2012. Various Body Measurements of Saanen Kids. Yüzüncü Y1l Üniversitesi, Veteriner Fakültesi Dergisi, 23:1, 23-28.

Boztepe S, Dağ B. 1995. İvesi Koyunlarında Vücut Ölçüleriyle Verim Özellikleri Arasındaki İlişkiler, Selçuk Üniversitesi, Ziraat Fakültesi Dergisi, 6:8,173-180.

Box GEP, Connor LR, Cousio WR, Davies OL, Himsworth FR, Sillitto GP. 1971. The Desing and Analysis of Industrial Experiments, T ve A Constable Ltd. Edinburg, 623.

Gürcan İS. 2000. Merinos Koyunlarında Beden Ölçüleri Kullanılarak İstatistiki Metotlarla Canlı Ağırlık Tahmini, Ankara Üniversitesi, Sağl1k Bilimleri Enstitüsü Doktora Tezi, Ankara.

Konar Keskin EB. 2010. Denizli Yöresi Bazı Kı1 Keçi Sürülerinde Vücut Ölçüleri İle Kondisyon Puanlarının Belirlenmesi. Adnan Menderes Üniversitesi, Fen Bilimleri Enstitüsü, Yüksek Lisans Tezi, Aydın.

MLC. 1981. Feeding The Ewe. Sheep Improvement Service. Technical Report. (Meat and Livestock Commission)

NRC. 2001. Nutrient Requirements of Dairy Cattle, 7th Rev. Ed. National Academy Press, Washington, DC.

Rae DO. 2002. Manogring for profit, Nutritional Priorities-Cow Age And Body Condition (http://gnv.ifas.ufl.edu/ animal/short95/rae.htm), Erişim Tarihi: 20.04.2016.

Riva J, Rizzi R, Marelli S, Cavalchini G. 2001. Body Measurements in Bergamasca Sheep, Small Ruminant Research, 221-227.

Russel AJF, Doney JM, Gunn RG. 1969. Subjective Assessment of Body Fat in Live Sheep. J. Agric. Sci. Camb. 72: 451454. 
Sandfort S.1982. Institutional and Economic Issues in the Development of Goat and Product Markets. Proceedings of the Third International Conference Goat Production and Diseasee. 10-15 January, Tucson, Arizona, USA.

Sarı M, ÖNK K, Aksoy AR, Tilki M, Adıgüzel Işık S. 2014. Hemşin Kuzularında Büyüme ve Bazı Vücut Ölçülerinin Belirlenmesi. Lalahan Hayvancılık Araştırma Enstitüsü Dergisi, 54:1, 15-20.

Spahr LI. 2006. Body Condition Scoring in Meat Goats. York County Extension Agent.

Şimşek ÜG, Bayraktar M. 2006. Kıl Keçisi ve Saanen x K1l keçisi $\left(\mathrm{F}_{1}\right)$ Melezlerine Ait

Büyüme ve Yaşama Gücü Özelliklerinin Araştırılması. Fırat Üniversitesi, Sağlık Bilimleri Dergisi, 20:3, 229-238.

Şimşek ÜG, Bayraktar M. 2007. K1l keçisi ve Saanen x Kıl keçisi $\left(\mathrm{F}_{1}\right)$ Melezlerinde Besi Performansı ve Karkas Özellikleri. Firat Üniversitesi, Sağlık Bilimleri Dergisi, 21:1, 15-20.
Şimşek ÜG, Bayraktar M, Gürses M. 2007. Saanen x Kıl Keçisi $F_{1}$ ve $G_{1}$ Melezlerinde Büyüme ve Yaşama Gücü Özelliklerinin Araştırılması, Fırat Üniversitesi, Sağlık Bilimleri Dergisi, 21:1, 21-26.

Tozlu H., 2006. Amasya İli Kıl Keçisi Islah Projesi Kapsamında Elde Edilen Saanen x K1l Keçisi $\left(\mathrm{F}_{1}\right)$ Melezleri İle Saf K1l Keçilerinin Büyüme ve Diğer Yetiştiricilik Özellikleri Bakımından Mukayesesi. Ondokuz Mayıs Üniversitesi, Fen Bilimleri Enstitüsü, Yüksek Lisans Tezi, Samsun.

Ünal N. 2002. Akkaraman ve Sakız x Akkaraman $F_{1}$ Kuzularda Yaşama Gücü, Büyüme ve Bazı Vücut Ölçüleri. Türk Veterinerlik ve Hayvancılık Dergisi, 26:1, 109-116.

Yalçıntan H, Ekiz B, Özcan M. 2012. Carcass Composition of Finished Kids From İndigenous and Dairy Breeds, Journal of the Faculty of Veterinary Medicine Istanbul University, 38, 43-50.

Wright IA, Russel AJF. 1984. Partition of Body Condition Scoring in Mature Cows Animal Production 38,23-32. 